\title{
Monitoring Planimetric and Volumetric Changes on Active Sand Dunes
}

James R Zimbelman ${ }^{1}$ and Andrew D Valdez ${ }^{2}$

${ }^{1}$ Center for Earth and Planetary Studies, National Air and Space Museum, Smithsonian Institution, Washington, DC

${ }^{2}$ Great Sand Dunes National Park and Preserve, Mosca, CO 



\section{Easting vs Northing: Inconsistent shift to the East}

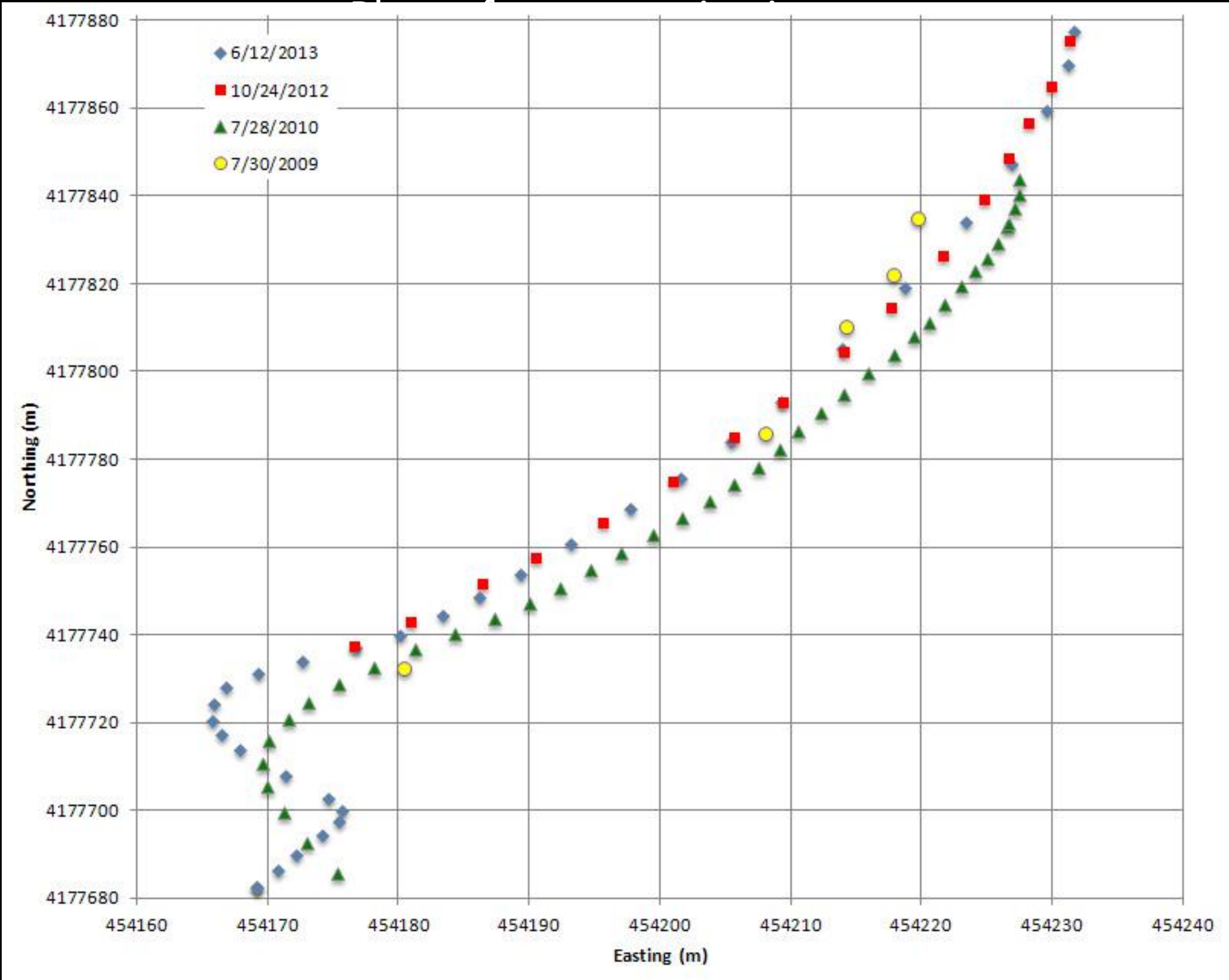




\section{Northing vs Elevation: Consistent extension to the North}

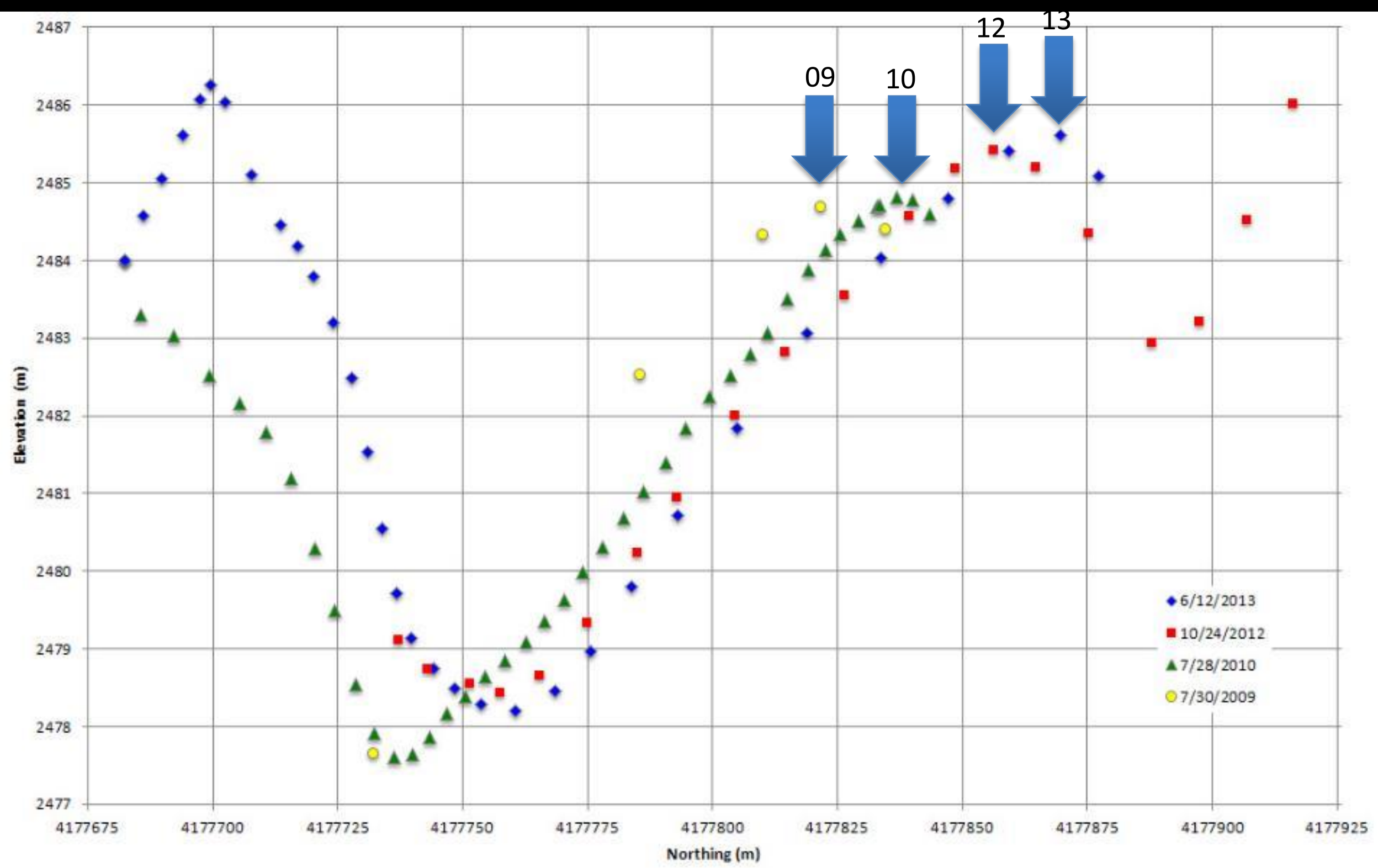





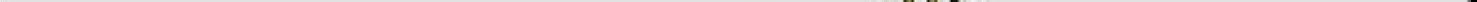


H Dune Triangulated Irregular Network

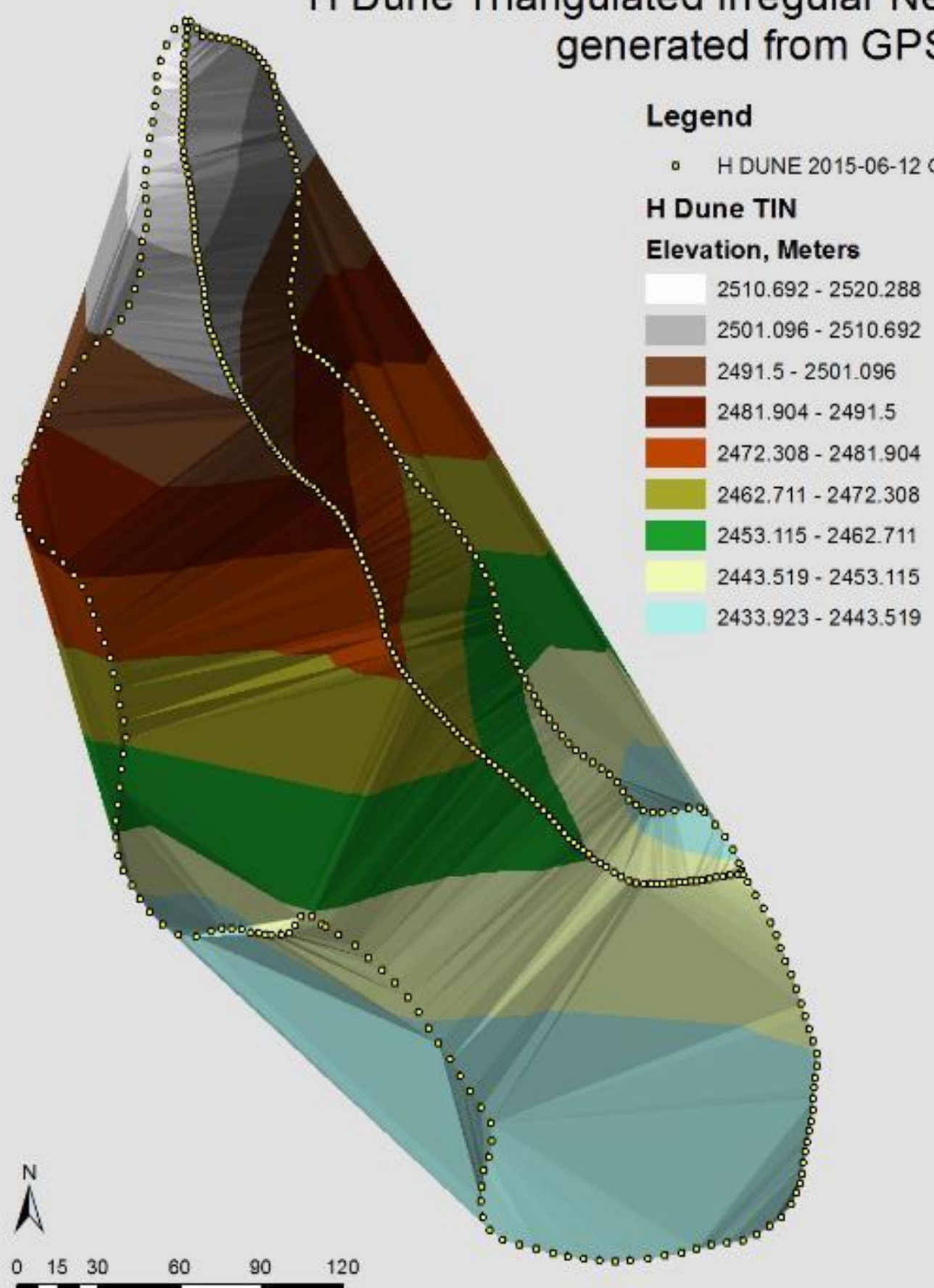

Meters 


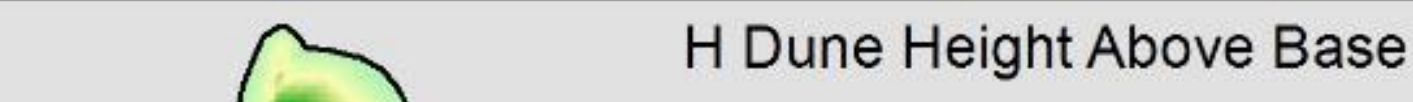

Legend

Dune Height above base meters

High : 15.4216

Low : -0.965576

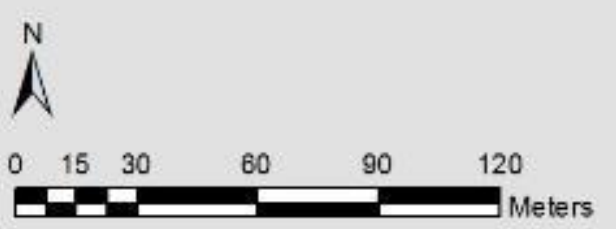




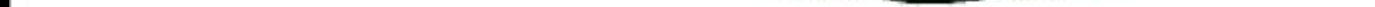




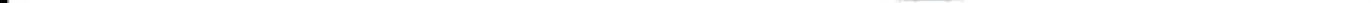




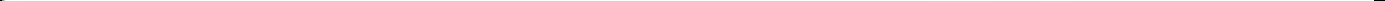




\section{Summary}

- Monitoring the crest of an active reversing dune showed inconsistent movement to $\mathrm{E}$, but extension to $\mathrm{N}$ (2009-2013).

- Documenting both crest and dune shape will provide a better record of how the sand is being actively redistributed. 